Check for updates

Cite this: Chem. Commun., 2020, 56,4708

Received 5th March 2020,

Accepted 19th March 2020

DOI: 10.1039/d0cc01722a

rsc.li/chemcomm

\section{Enhanced single-molecule magnetism in dysprosium complexes of a pristine cyclobutadienyl ligand $\dagger$}

\author{
James P. Durrant, (D) ${ }^{\text {ab }}$ Jinkui Tang, (D) ${ }^{c}$ Akseli Mansikkamäki (D)*d and \\ Richard A. Layfield (D)*a
}

Intact transfer of the cyclobutadienyl ligand $\left[\mathrm{C}_{4}\left(\mathrm{SiMe}_{3}\right)_{4}\right]^{2-}$ to yttrium and dysprosium (M) produces the half-sandwich complexes

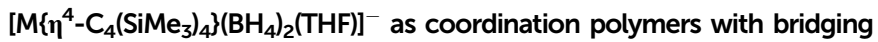
sodium or potassium ions. The dysprosium versions are single-molecule magnets (SMMs) with energy barriers of $371(7)$ and $357(4) \mathrm{cm}^{-1}$, respectively. The pristine cyclobutadienyl ligands provide a strong axial crystal field that enhances the SMM properties relative to related cyclopentadienyl compounds.

Single-molecule magnets (SMMs) are coordination compounds in which individual molecules have a bi-stable magnetic ground state. ${ }^{1}$ SMMs based on lanthanides dominate the landscape, ${ }^{2,3}$ with terbium and dysprosium being the most popular owing to the strong spin-orbit coupling and magnetic anisotropy of $\mathrm{Tb}^{3+}$ and $\mathrm{Dy}^{3+}$ ions, which are required to observe magnetic hysteresis. Indeed, the properties of $\mathrm{Dy}^{3+}$ are so well-suited to the task that dysprosium compounds not showing SMM traits are almost as remarkable as those that do. Beyond the fundamental interest in SMMs, some key systems have been used as components in prototype molecular spintronic devices, such as spin valves and spin transistors. ${ }^{4,5}$

Two parameters often used to quantify SMM performance are the effective energy barrier to reversal of the magnetization $\left(U_{\text {eff }}\right)$ and the magnetic blocking temperature $\left(T_{\mathrm{B}}\right)$, which can be defined as the highest temperature at which magnetic hysteresis occurs. ${ }^{6}$ Whilst SMMs with large $U_{\text {eff }}$ values are not uncommon,

\footnotetext{
${ }^{a}$ Department of Chemistry, School of Life Sciences, University of Sussex, Brighton, BN1 9QR, UK. E-mail: R.Layfield@sussex.ac.uk

${ }^{b}$ School of Chemistry, The University of Manchester, Oxford Road, Manchester, M13 9PL, UK

${ }^{c}$ Changchun Institute of Applied Chemistry, Chinese Academy of Sciences, Renmin Street 5626, 130022 Changchun, China

${ }^{d}$ NMR Research Unit, University of Oulu, P.O. Box 8000, FI-90014, Finland. E-mail: Akseli.Mansikkamaki@oulu.fi

$\dagger$ Electronic supplementary information (ESI) available: Synthesis details, spectroscopic characterization, magnetic measurements and computational details. CCDC 1987236-1987239. For ESI and crystallographic data in CIF or other electronic format see DOI: 10.1039/d0cc01722a
}

examples with blocking temperatures above the liquid-helium regime are rare. Some of us recently reported the metallocene $\left[\left(\mathrm{C}_{5} \mathrm{Me}_{5}\right) \operatorname{Dy}\left(\mathrm{C}_{5}{ }^{\mathrm{i}} \mathrm{Pr}_{5}\right)\right]^{+},{ }^{7}$ which has a blocking temperature of $80 \mathrm{~K}$, i.e. above the boiling point of liquid nitrogen, and the broader significance of this system is that it provides a blueprint for further improving the performance of dysprosium SMMs through targeted modifications to the chemistry. ${ }^{8}$ In the case of dysprosium, large $U_{\text {eff }}$ and $T_{\mathrm{B}}$ values occur when the crystal field is both strong and highly axial. Some increases in $T_{\mathrm{B}}$ beyond $80 \mathrm{~K}$ may be achievable with metallocene SMMs by modifying the substituents, yet more profound changes are required to observe major improvements in performance. Therefore, we have recently focused on the cyclobutadienyl (Cb) ligand in f-element chemistry. ${ }^{9-11}$

The rationale for replacing $\mathrm{Cp}$ ligands with $\mathrm{Cb}$ in dysprosium SMMs is based on the idea that the greater charge density of the four-membered ring, which is $6 \pi$ aromatic and therefore dianionic, will produce a stronger (axial) crystal field. As such, (half-)sandwich $\mathrm{Cb}$ complexes of dysprosium should have improved SMM properties relative to analogous Cp complexes. To test this, we synthesized two complexes containing the half-sandwich unit $\left\{\eta^{4}-\mathrm{C}_{4}\left(\mathrm{SiMe}_{3}\right)_{4}\right\}$ Dy by reacting $\left[\mathrm{Dy}\left(\mathrm{BH}_{4}\right)_{3}(\mathrm{THF})_{3}\right]$ with the alkali metal cyclobutadienyl salts $\left[\mathrm{A}_{2}\left\{\mathrm{C}_{4}\left(\mathrm{SiMe}_{3}\right)_{4}\right\}\right](\mathrm{A}=\mathrm{Na}, \mathrm{K})$ in benzene according to Scheme 1 . The products were identified by X-ray crystallography as the coordination polymers $\left[\mathrm{Dy}\left\{\eta^{4}\right.\right.$ $\left.\left.\mathrm{C}_{4}\left(\mathrm{SiMe}_{3}\right)_{4}\right\}\left(\mathrm{BH}_{4}\right)_{2}(\mathrm{THF}) \mathrm{Na}\right]_{\infty}\left(\mathbf{1}_{\text {Dy }}\right)$ and $\left[\mathrm{Dy}\left\{\eta^{4}-\mathrm{C}_{4}\left(\mathrm{SiMe}_{3}\right)_{4}\right\}\left(\mathrm{BH}_{4}\right)_{2^{-}}\right.$ $(\mathrm{THF}) \mathrm{K}]_{\infty}\left(2_{\mathrm{Dy}}\right)$. To broaden the scope of the synthetic method, the analogous yttrium compounds $\left[\mathrm{Y}\left\{\eta^{4}-\mathrm{C}_{4}\left(\mathrm{SiMe}_{3}\right)_{4}\right\}\left(\mathrm{BH}_{4}\right)_{2}\right.$ $(\mathrm{THF}) \mathrm{Na}]_{\infty}\left(\mathbf{1}_{\mathbf{Y}}\right)$ and $\left[\mathrm{Y}\left\{\eta^{4}-\mathrm{C}_{4}\left(\mathrm{SiMe}_{3}\right)_{4}\right\}\left(\mathrm{BH}_{4}\right)_{2}(\mathrm{THF}) \mathrm{K}\right]_{\infty}\left(\mathbf{2}_{\mathbf{Y}}\right)$ were also synthesized (Tables S1-S3 and Fig. S1-S11, ESI $\dagger$ ).

The structures of $\mathbf{1}_{\mathbf{Y}}$ and $\mathbf{1}_{\mathbf{D y}}$ are alike, hence only the dysprosium version is described here (see Fig. S13 for details of $\mathbf{1}_{\mathbf{Y}}$ ). The structure of $\mathbf{1}_{\mathbf{D y}}$ consists of an asymmetric unit in which two similar yet crystallographically unique half-sandwich units alternate along zigzag polymeric chains (Fig. 1). Each dysprosium centre is ligated by an $\eta^{4}-\mathrm{C}_{4}\left(\mathrm{SiMe}_{3}\right)_{4}$ ligand, a bridging borohydride ligand, a terminal $\kappa^{3}$-bound borohydride ligand and a THF ligand. The different coordination modes of 


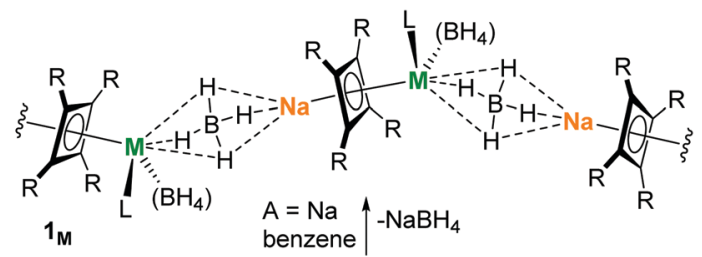

$\left[\mathrm{M}\left(\mathrm{BH}_{4}\right)_{3}(\mathrm{THF})_{3}\right]+\left[\mathrm{A}_{2}\left\{\mathrm{C}_{4}\left(\mathrm{SiMe}_{3}\right)_{4}\right\}\right]$ \begin{tabular}{l|l}
$\mathrm{A}=\mathrm{K}$ & $\mathrm{KBH}$ \\
benzene & $-\mathrm{KBH}_{4}$
\end{tabular}

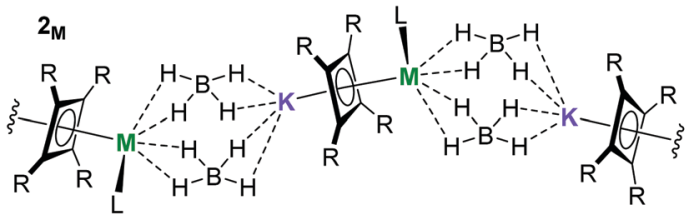

Scheme 1 Synthesis of $\mathbf{1}_{\mathbf{M}}$ and $\mathbf{2}_{\mathbf{M}}\left(\mathbf{M}=\mathrm{Y}, \mathrm{Dy} ; \mathrm{R}=\mathrm{SiMe}_{3}, \mathrm{~L}=\mathrm{THF}\right)$.
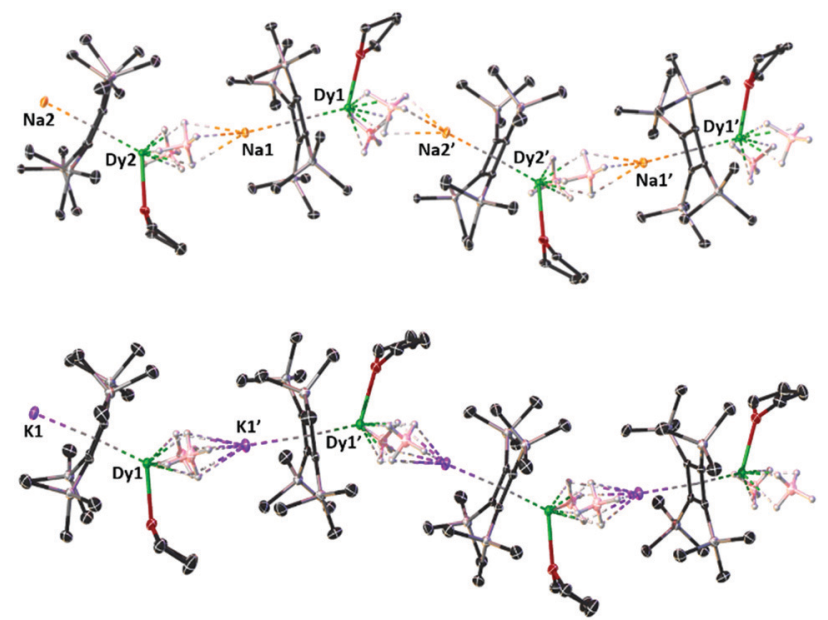

Fig. 1 Thermal ellipsoid representations (50\% probability) of segments of the polymeric structures of $\mathbf{1}_{\mathrm{Dy}}$ (top) and $\mathbf{2}_{\mathrm{Dy}}$ (bottom). $\mathrm{H}=$ white, $\mathrm{B}=$ pink, $\mathrm{C}=$ black, $\mathrm{O}=$ red, $\mathrm{Na}=$ orange, $\mathrm{Si}=$ grey, $\mathrm{K}=$ lilac, $\mathrm{Dy}=$ green. For clarity, only the hydrogen atoms bound to boron are shown.

the borohydride ligands in $\mathbf{1}_{\text {Dy }}$ are reflected in the FTIR spectrum, which shows absorptions at $2450 \mathrm{~cm}^{-1}$ and $2100-$ $2300 \mathrm{~cm}^{-1}$ for the terminal and bridging $\mathrm{B}-\mathrm{H}$ bonds, respectively (Fig. S12, ESI $\dagger$ ). From Dy1, the polymer assembles through the $\mathrm{Cb}$ ligand in one direction with a $\mu: \eta^{4}$-interaction with $\mathrm{Na1}$, and in the opposite direction via coordination of the bridging borohydride ligand to Na2. The Dy-C distances and the Dy- $\mathrm{Cb}_{\text {cent }}$ distance in molecule 1 of $\mathbf{1}_{\text {Dy }}$ are $2.489(8)-2.500(8) \AA$ and $2.262(4) \AA$, respectively, the $\mathrm{Na}-\mathrm{C}$ and $\mathrm{Na}-\mathrm{Cb}_{\text {cent }}$ distance are 2.591(9)2.637(9) A and 2.392(6) A, respectively, and the Dy-Cb-Na angle is $178.4(2)^{\circ}$. The solution-phase ${ }^{1} \mathrm{H}$ and ${ }^{13} \mathrm{C}$ NMR spectra of $\mathbf{1}_{\mathbf{Y}}$ in THF- $\mathrm{D}_{8}$ are consistent with the solid-state structure, as are the ${ }^{23} \mathrm{Na}$ and ${ }^{29} \mathrm{Si} \mathrm{NMR}$ spectra, which feature resonances at $\delta=-4.26 \mathrm{ppm}$ and $\delta=-22.69 \mathrm{ppm}$, respectively (Fig. S1-S4, $\mathrm{ESI} \dagger)$. The ${ }^{11} \mathrm{~B}$ and ${ }^{11} \mathrm{~B}\left\{{ }^{1} \mathrm{H}\right\}$ spectra both contain broad resonances centred on $\delta=-23.00 \mathrm{ppm}$, with unresolved ${ }^{1} \mathrm{~J}$ coupling to the protons (Fig. S5 and S6, ESI $\dagger$ ), which may point to the borohydride ligands in $\mathbf{1}_{\mathbf{Y}}$ undergoing exchange in solution.
The structures of $\mathbf{2}_{\mathbf{Y}}$ and $\mathbf{2}_{\mathbf{D y}}$ are comparable to those of the sodium analogues, consisting of zigzag chains based on $\left[\left\{\eta^{4}-\mathrm{C}_{4}\left(\mathrm{SiMe}_{3}\right)_{4}\right\} \mathrm{M}\left(\mathrm{BH}_{4}\right)_{2}(\mathrm{THF}) \mathrm{K}\right]$ units (Fig. 1 and Fig. S14, ESI $\dagger)$. The structural similarities are reflected in the FTIR spectra of all four compounds, which feature absorptions at similar frequencies in the region $450-4000 \mathrm{~cm}^{-1}$ (Fig. S12, ESI $\dagger$ ). The only notable difference in the structures of $\mathbf{1}_{\mathbf{M}}$ and $\mathbf{2}_{\mathbf{M}}$ is that both borohydride ligands in the latter bridge between potassium and the rare earth element owing to the larger radius of potassium relative to sodium. In $\mathbf{2}_{\mathrm{Dy}}$, the Dy-C, Dy-Cb $\mathrm{b}_{\text {cent }}$, $\mathrm{K}-\mathrm{C}$ and $\mathrm{K}-\mathrm{Cb}_{\text {cent }}$ distances are 2.473(6)-2.519(6) $\mathrm{A}, 2.264(3) \AA$, 2.890(6)-2.929(6) A and 2.730(3) A, respectively, and the Dy-Cb-K angle is $176.46(13)^{\circ}$ (details of $2_{\mathbf{Y}}$ are provided in the ESI $\dagger$ ). In solution, each ${ }^{1} \mathrm{H}$ and ${ }^{13} \mathrm{C}$ environment in $2_{\mathbf{Y}}$ produces a characteristic resonance in the NMR spectrum (Fig. S7 and S8, ESI $\dagger$ ), with the ${ }^{11} \mathrm{~B}\left\{{ }^{1} \mathrm{H}\right\}$ and ${ }^{29} \mathrm{Si}$ NMR spectra showing resonances at $\delta=-27.01 \mathrm{ppm}$ and $-22.58 \mathrm{ppm}$, respectively (Fig. S9 and S11, $\mathrm{ESI} \dagger)$. The ${ }^{11} \mathrm{~B}\left\{{ }^{1} \mathrm{H}\right\}$ resonance is sharp and the ${ }^{1} J$ coupling $(84 \mathrm{~Hz})$ to the protons is well resolved as a quintet in the ${ }^{11} \mathrm{~B} \mathrm{NMR}$ spectrum (Fig. S10, ESI $\dagger$ ), suggesting that the borohydride ligands in $2_{\mathbf{Y}}$ are not in exchange.

The cyclobutadienyl chemistry of the f-elements is in its infancy, with the first examples being reported only recently. ${ }^{9-12}$ In stark contrast to the variety of substituents used with cyclopentadienyl ligands, the scope for substituent variation with cyclobutadienyl ligands is severely restricted owing to the inherent instability of anti-aromatic, strained cyclobutadiene pro-ligands. Currently, the only cyclobutadiene that can be isolated in synthetically useful amounts is the tetrakis(trimethylsilyl) derivative employed in this study. ${ }^{13}$ However, a drawback of using $\mathrm{C}_{4}\left(\mathrm{SiMe}_{3}\right)_{4}$ with f-elements is that the methyl substituents are prone to deprotonation, which results in formation of tuck-in complexes, i.e. additional coordination to the metal by a pendant $\left[\mathrm{CbSiMe}_{2} \mathrm{CH}_{2}\right]^{-}$group. ${ }^{9}$ Furthermore, the dianionic cyclobutadienyl ring is susceptible to protonation (sometimes from one of its own $\mathrm{SiMe}_{3}$ substituents), leading to loss of aromaticity and formation of $\eta^{3}$-cyclobutenyl ligands. ${ }^{10}$ In light of this, the intact transfer of $\left[\mathrm{C}_{4}\left(\mathrm{SiMe}_{3}\right)_{4}\right]^{2-}$ to yttrium and dysprosium in $\mathbf{1}_{\mathbf{M}}$ and $\mathbf{2}_{\mathbf{M}}$ is noteworthy. Compounds $\mathbf{1}_{\mathbf{D y}}$ and $\mathbf{2}_{\mathbf{D y}}$ therefore provide the first opportunity to study the influence of a pristine cyclobutadienyl ligand on the dynamic magnetic properties of dysprosium.

The magnetic susceptibility of $\mathbf{1}_{\text {Dy }}$ and $\mathbf{2}_{\text {Dy }}$ was measured in static (DC) and dynamic (AC) fields using a Magnetic Property Measurement System. In a static field of 1000 Oe, the temperature dependence of the molar magnetic susceptibility $\left(\chi_{\mathrm{M}}\right)$ for both compounds is typical of $\mathrm{Dy}^{3+}$ with a ${ }^{6} \mathrm{H}_{15 / 2}$ ground multiplet (Fig. S15 and S25, ESI $\dagger$ ). Thus, $\chi_{\mathrm{M}} T$ at $300 \mathrm{~K}$ is $13.46 \mathrm{~cm}^{3} \mathrm{~K} \mathrm{~mol}^{-1}$ and $13.52 \mathrm{~cm}^{3} \mathrm{~K} \mathrm{~mol}^{-1}$ for $\mathbf{1}_{\text {Dy }}$ and $\mathbf{2}_{\text {Dy }}$, respectively, with a gradual decrease occurring down to about $9 \mathrm{~K}$, when a sharper decrease is observed and values of $9.60 \mathrm{~cm}^{3} \mathrm{~K} \mathrm{~mol}{ }^{-1}$ and $9.13 \mathrm{~cm}^{3} \mathrm{~K} \mathrm{~mol}^{-1}$, respectively, are reached at $2 \mathrm{~K}$. The SMM properties of the two compounds were then characterized using the frequency-dependence of the imaginary component of the AC susceptibility, $\chi^{\prime \prime}(\nu)$, at various temperatures. In the case of $\mathbf{1}_{\text {Dy }}$, maxima in $\chi^{\prime \prime}(\nu)$ were observed from $1.9 \mathrm{~K}$ to $39 \mathrm{~K}$, however up to $9 \mathrm{~K}$ the frequency at which the maxima occur is essentially 

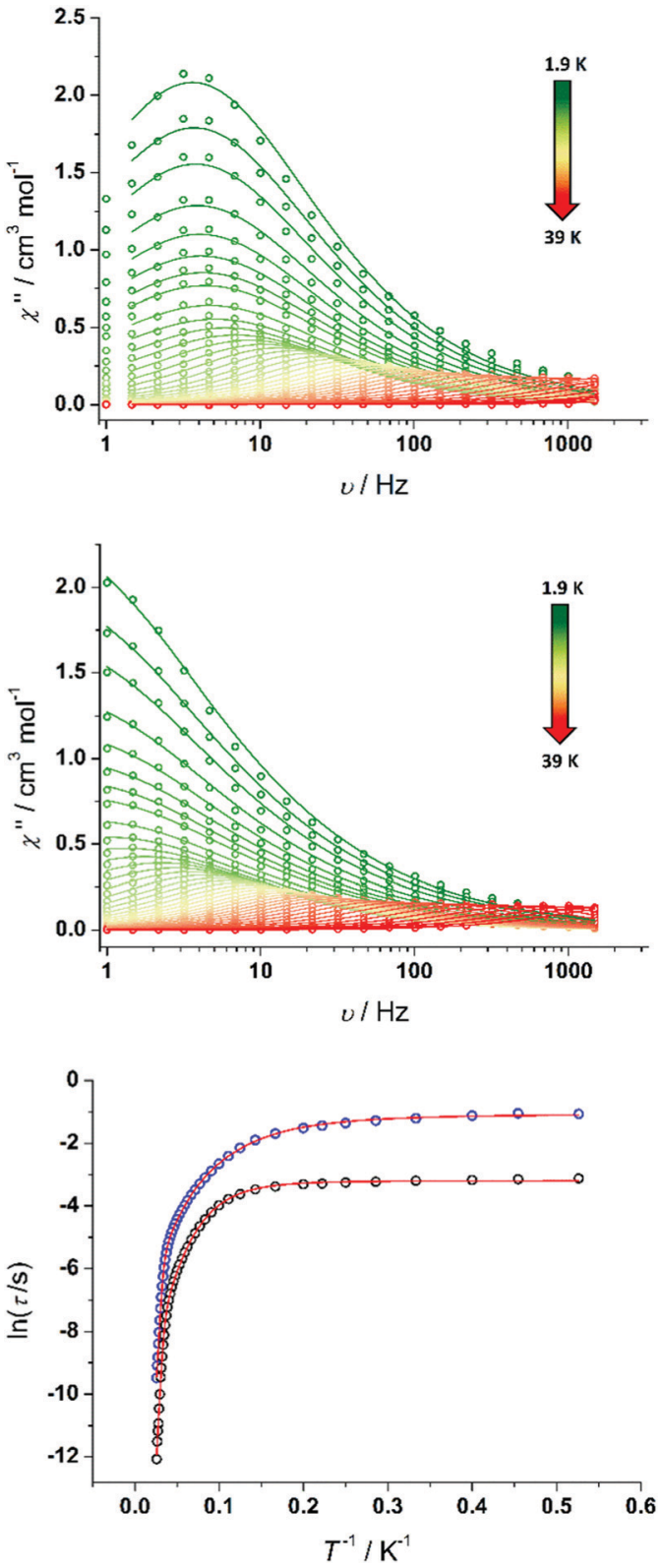

Fig. 2 Frequency dependence of the out-of-phase susceptibility for $\mathbf{1}_{\mathrm{Dy}}$ (top) and $\mathbf{2}_{\mathrm{Dy}}$ (middle) in zero DC field; solid lines represent fits to the data using the parameters stated in the ESI. $\dagger$ Bottom: Temperature dependence of the relaxation times for $\mathbf{1}_{\text {Dy }}$ (black circles) and $\mathbf{2}_{\text {Dy }}$ (blue circles) using the parameters stated in the main text.

temperature independent (Fig. 2). At higher temperatures, the maxima shift to higher frequencies before reaching the upper limit of the instrument at $1488 \mathrm{~Hz}$. Fits of the AC susceptibility using the standard Cole-Cole method and $\alpha$-parameters of $0-0.36$ allowed the relaxation times $(\tau)$ to be extracted (Fig. S17-S22 and Table S4, ESI $\dagger$ ). Plotting $\tau$ vs. $T^{-1}$ gave good fits of the data using $\tau^{-1}=\tau_{0}{ }^{-1} \mathrm{e}^{-U_{\text {eff }} / k_{\mathrm{B}} T}+C T^{\mathrm{n}}+\tau_{\mathrm{QTM}}{ }^{-1}$, where the Orbach parameters are

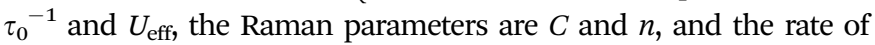
quantum tunnelling of the magnetization (QTM) is $\tau_{\mathrm{QTM}}{ }^{-1}$ (Fig. 2). The analysis for $\mathbf{1}_{\mathrm{Dy}}$ gave $U_{\mathrm{eff}}=371(7) \mathrm{cm}^{-1}$ (or $534(10) \mathrm{K}$ ) with $\tau_{0}=7.8(2) \times 10^{-12} \mathrm{~s}, C=0.0041(7) \mathrm{s}^{-1} \mathrm{~K}^{-n}, n=3.85(6)$ and
$\tau_{\mathrm{QTM}}=0.041(1) \mathrm{s}$. The $\chi^{\prime \prime}(\nu)$ data for $2_{\mathrm{Dy}}$ (Fig. 2 and Fig. S27-S32, Table S5, ESI $\dagger$ ) are similar to that of $\mathbf{1}_{\mathbf{D y}}$, and the same fitting procedure with $\alpha=0-0.31$ gave $U_{\text {eff }}=357(4) \mathrm{cm}^{-1}$ (or $513(6) \mathrm{K}$ ), with $\tau_{0}=1.6(3) \times 10^{-10} \mathrm{~s}, C=0.014(1) \mathrm{s}^{-1} \mathrm{~K}^{-n}, n=2.89(2)$ and $\tau_{\mathrm{QTM}}=0.35(1) \mathrm{s}$ (Fig. 2).

The temperature dependence of $\tau$ for $\mathbf{1}_{\mathbf{D y}}$ and $\mathbf{2}_{\mathbf{D y}}$ implies that magnetic relaxation is characterized by Orbach processes from $39 \mathrm{~K}$ down to about $10 \mathrm{~K}$, and then QTM dominates. A qualitative explanation for the SMM behaviour is that each $\mathrm{Dy}^{3+}$ ion experiences an axial crystal field provided by the cyclobutadienyl ligand, with the THF and borohydride ligands providing a competing equatorial crystal field, as evidenced by the fast QTM at lower temperatures. Support for this idea can obtained upon comparison of $\mathbf{1}_{\mathbf{D y}}$ and $\mathbf{2}_{\mathbf{D y}}$ with the halfsandwich complex $\left[\left(\eta^{5}-\mathrm{C}_{5}{ }^{\mathrm{i}} \mathrm{Pr}_{5}\right) \operatorname{Dy}\left(\mathrm{BH}_{4}\right)_{2}(\mathrm{THF})\right]$, an SMM with a barrier of $241(7) \mathrm{cm}^{-1}$ in zero DC field. ${ }^{7}$ The differing barrier heights in these $\mathrm{Cb}$ - and $\mathrm{Cp}$-ligated half-sandwich compounds is presumably related to the stronger axial crystal field provided by the pristine dianionic $\left[\mathrm{C}_{4}\left(\mathrm{SiMe}_{3}\right)_{4}\right]^{2-}$ ligand relative to that provided by the monoanionic $\left[\mathrm{C}_{5}{ }^{\mathrm{i}} \mathrm{Pr}_{5}\right]^{-}$ligand.

A quantitative description of the electronic structure of $\mathbf{2}_{\mathbf{D y}}$ was obtained by performing multireference $a b$ initio calculations on a model consisting of three $\left[\left\{\eta^{4}-\mathrm{C}_{4}\left(\mathrm{SiMe}_{3}\right)_{4}\right\} \mathrm{M}\left(\mathrm{BH}_{4}\right)_{2}(\mathrm{THF})\right]^{-}$ units and two bridging $\mathrm{K}^{+}$ions (Fig. 3). ${ }^{14-21}$ The $\mathrm{Dy}^{3+}$ ions in the two capping half-sandwich units were replaced by $\mathrm{Y}^{3+}$ in order to study only the central $\mathrm{Dy}^{3+}$ ion. The positions of the hydrogen atoms were optimized using density functional theory (DFT) while the positions of heavier atoms were fixed to their crystalstructure coordinates. DFT calculations were carried out to ensure that no significant changes in the charge distribution of the central fragment would be obtained by including a longer fragment of $\mathbf{2}_{\mathbf{D y}}$.
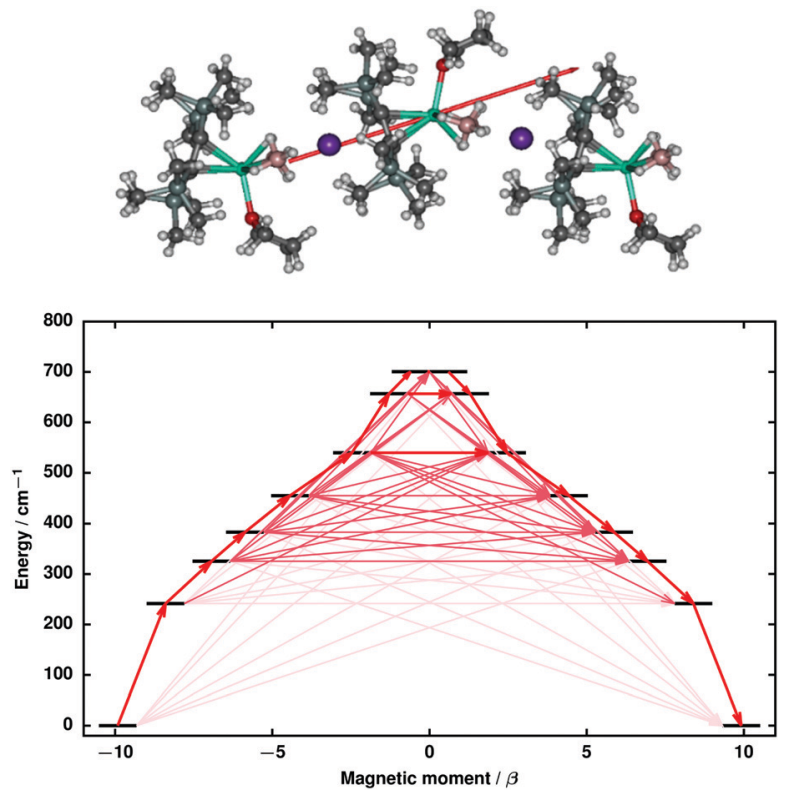

Fig. 3 Top: The principal magnetic axis of the ground doublet of $D y^{3+}$ in $\mathbf{2}_{\text {Dy }}$. Bottom: The qualitative relaxation barrier in $\mathbf{2}_{\text {Dy }}$. The arrows represent transition magnetic moments, with stronger arrows indicating larger values. 
The principal magnetic axis of the ground Kramers doublet (KD) is shown in Fig. 3 and the properties of the eight lowest Kramers doublets (KDs) arising from the crystal-field split ground ${ }^{6} \mathrm{H}_{15 / 2}$ multiplet of the $\mathrm{Dy}^{3+}$ ion are listed in Table S5. The direction of the principal magnetic axis in the ground $\mathrm{KD}$ is clearly set by the strong axial interaction between $\mathrm{Dy}^{3+}$ and the $\left[\mathrm{C}_{4}\left(\mathrm{SiMe}_{3}\right)_{4}\right]^{2-}$ ligand. The ground $\mathrm{KD}$ has an axial $g$-tensor with vanishingly small transverse components suggesting that QTM should be slow at zero field. The transverse components become significant in the second excited $\mathrm{KD}$, indicating that the barrier for the relaxation of magnetization is crossed at that point. This gives a predicted effective barrier height of 326 $\mathrm{cm}^{-1}$, which is in good agreement with the experimentally determined value of $357(4) \mathrm{cm}^{-1}$ for $\mathbf{2}_{\text {Dy }}$. The transverse components are small enough that transitions up to the fourth excited could, in principle, be possible, but this is improbable.

The effective energy barrier was also modeled for $\mathbf{2}_{\mathbf{D y}}$ by calculating the transition magnetic moment matrix elements between the different states in the ground multiplet following a well-established method. ${ }^{20}$ The results (Fig. 3 and Table S6, ESI $\dagger$ ) indicate that the barrier is crossed at the second excited KD. It should be noted that values of the transition magnetic moments remain relatively small up to the fifth excited $\mathrm{KD}$ indicating that even minor modifications to the molecular structure, and hence the crystal-field, could significantly increase the barrier height.

Further insight into the electronic structure of $\mathbf{2}_{\mathbf{D y}}$ was obtained by calculating the $a b$ initio crystal-field parameters according to a well-known methodology (Tables S7 and S8, ESI $\dagger$ ). ${ }^{21}$ The axial second-rank parameter is $B_{20}=-377 \mathrm{~cm}^{-1}$, which creates a relatively strong axial field. However, the off-diagonal secondrank parameters also have large magnitudes, i.e. $\left|B_{2 \pm 1}\right|=$ $15 \mathrm{~cm}^{-1}$ and $\left|B_{2 \pm 2}\right|=19 \mathrm{~cm}^{-1}$, leading to significant mixing of the different states characterized by a definite projection of the total angular momentum. Compared to $\left[\left(\mathrm{C}_{5} \mathrm{Me}_{5}\right) \operatorname{Dy}\left(\mathrm{C}_{5}{ }^{\mathrm{i}} \mathrm{Pr}_{5}\right)\right]^{+},{ }^{7}$ the off-diagonal second-rank parameters have very similar magnitudes in $\mathbf{2}_{\mathbf{D y}}$, but the axial parameters are roughly four times smaller. This means that the axiality in $\mathbf{2}_{\mathbf{D} y}$, originating from the interaction with the $\left[\mathrm{C}_{4}\left(\mathrm{SiMe}_{3}\right)_{4}\right]^{2-}$ ligand, is not strong enough to overcome the significant non-axial components of the crystal field arising from the $\left[\mathrm{BH}_{4}\right]^{-}$and THF ligands.

In summary, the main finding in this study confirms our hypothesis that pristine cyclobutadienyl ligands can indeed generate much stronger axial crystal fields at dysprosium centres than more commonly used cyclopentadienyl ligands. In light of this, if a near-linear dysprosium complex of the type $[(\mathrm{Cb}) \mathrm{Dy}(\mathrm{Cp})]$ or $\left[\mathrm{Cb}_{2} \mathrm{Dy}\right]^{-}$can be synthesized, the SMM properties should be competitive with those of current benchmark metallocene systems of the type $\left[\mathrm{Cp}_{2} \mathrm{Dy}\right]^{+}$.

For financial support, we thank the University of Sussex, the ERC (CoG 646740), the EPSRC (EP/M022064/1), the National Natural Science Foundation of China (Grants 21525103 and 21871247), the Magnus Ehrnrooth Foundation, the CSC-IT Center for Science in Finland, the Finnish Grid and Cloud Infrastructure (urn:nbn:fi:research-infras-2016072533), the University of Oulu (Kvantum Institute) and Prof. H. M. Tuononen (University of Jyväskylä) for computational resources. JT and RAL also thank the Royal Society for a Newton Advanced Fellowship (NA160075).

\section{Conflicts of interest}

There are no conflicts to declare.

\section{Notes and references}

1 F.-S. Guo, A. K. Bar and R. A. Layfield, Chem. Rev., 2019, 119, 847.

2 J. Lu, M. Guo and J. Tang, Chem. - Asian J., 2017, 12, 2772.

3 L. Escalera-Moreno, J. J. Baldoví, A. Gaita-Ariño and E. Coronado, Inorg. Chem., 2019, 58, 11883.

4 J. J. Le Roy, J. Cremers, I. A. Thomlinson, M. Slota, W. K. Myers, P. H. Horton, S. J. Coles, H. L. Anderson and L. Bogani, Chem. Sci., 2018, 9, 8474.

5 E. Coronado, Nat. Rev. Mater., 2020, 5, 87.

6 J. D. Rinehart and J. R. Long, Chem. Sci., 2011, 2, 2078.

7 F.-S. Guo, B. M. Day, Y.-C. Chen, M.-L. Tong, A. Mansikkamäki and R. A. Layfield, Science, 2018, 362, 1400.

8 B. M. Day, F.-S. Guo and R. A. Layfield, Acc. Chem. Res., 2018, 51, 1880.

9 B. M. Day, F.-S. Guo, S. R. Giblin, A. Sekiguchi, A. Mansikkamäki and R. A. Layfield, Chem. - Eur. J., 2018, 24, 16779.

10 A. Chakraborty, B. M. Day, J. P. Durrant, M. He, J. Tang and R. A. Layfield, Organometallics, 2020, 39, 8.

11 N. Tsoureas, A. Mansikkamäki and R. A. Layfield, Chem. Commun., 2020, 56, 944.

12 J. T. Boronski, L. R. Doyle, J. A. Seed, A. J. Wooles and S. T. Liddle, Angew. Chem., Int. Ed., 2020, 59, 295.

13 A. Sekiguchi, T. Matsuo and H. Watanabe, J. Am. Chem. Soc., 2000, 122, 5652.

14 B. O. Roos, in Advances in Chemical Physics: Ab Initio Methods in Quantum Chemistry II, ed. K. P. Lawley, Wiley, New York, NY, USA, 1987, vol. 69, pp. 399-455.

15 P. Siegbahn, A. Heiberg, B. Roos and B. Levy, Phys. Scr., 1980, 21, 323.

16 B. O. Roos, P. R. Taylor and P. E. M. Siegbahn, Chem. Phys., 1980, 48, 157.

17 P. E. M. Siegbahn, J. Almlöf, A. Heiberg and B. O. Roos, J. Chem. Phys., 1981, 74, 2384.

18 P. A. Malmqvist, B. O. Roos and B. Schimmelpfennig, Chem. Phys. Lett., 2002, 357, 230.

19 L. F. Chibotaru and L. Ungur, J. Chem. Phys., 2012, 137, 64112.

20 L. Ungur, M. Thewissen, J.-P. Costes, W. Wernsdorfer and L. F. Chibotaru, Inorg. Chem., 2013, 52, 6328.

21 L. Ungur and L. F. Chibotaru, Chem. - Eur. J., 2017, 23, 3708. 